\section{Information acquisition and exchange within cryptozoological virtual communities}

\author{
David Dmytriw
}

\section{The Author}

David Dmytriw graduated with an MA in Information and Library Management from Northumbria University in 2003. Since graduating, he has pursued a career in librarianship. His previous degrees are in Sociology and Social Research.

\section{Email: david dmytriw@yahoo.co.uk}

\section{The Occasion}

This is a summary of a dissertation submitted for the Information and Library Management degree at Northumbria University in 2002. The dissertation was awarded the 2004 LIRG Postgraduate Prize.

\section{Acknowledgements}

I would like to thank my dissertation supervisor, Dr. Alison Pickard, for her help, advice and support during the research process and completion of the dissertation. Thanks also to the virtual community members and moderators without whom this research would not have been possible.
Thanks to Computer-Mediated Communication (CMC) offered by the internet, people are now able to seek out others with similar interests, views or occupations and communicate with them online. We can read each other's views or data, regardless of our geographical location. We can communicate 'live' (such as in internet relay chat) or without having to be simultaneously present (via newsgroups, email discussion lists or message boards). In recent years, established groups of individuals ranging from a handful to hundreds or even thousands have been engaged in regular CMC with each other. This phenomenon has come to be known as 'virtual communities'.

I have been researching the nature of virtual communities and how their members acquire and exchange information. The communities in my study are all related to one specific discipline: cryptozoology - the investigation of mythical animals such as Bigfoot and the Loch Ness Monster.

My research reveals a number of findings that challenge some widely-held beliefs and perceptions. The results show that the groups are not founded on a desire to create a sense of 'community' as a substitute for crumbling offline ones. 'Community' arises, but the motivation is to swap and discuss information. Young people are not favouring the internet in place of traditional information resources. In fact, it acts as a pointer to books and public libraries and a wide variety of traditional information sources that are consulted offline. Online activity is not conducted at the expense of offline activity - it strengthens and spawns it, leading to face-to-face and telephone contact. It is not a substitute.

Virtual community membership is not the preserve of teenagers interested in idle chat, as popular perceptions often have it. Nearly half of the sample was made up of people aged over 40. For disabled and isolated individuals, the communities act as a lifeline, bringing human contact where otherwise there might be none. On the subject of virtual community membership, it was found to be long lasting and committed, not simply fleeting and temporary. 
Also, most members do not passively accept information, as is often thought. Instead, both members and those moderating the groups apply a variety of methods to judge and evaluate information.

The findings also shed light on hitherto unexplored areas, such as the habits of 'lurkers' - members of communities who read messages from others but do not actively contribute themselves. It was found that some of them do contribute, but only offline. And while some communities prefer to remain separate entities when it comes to sharing information, others support each other in building knowledge, realising that more can be achieved by pooling their data and findings.

One of the benefits of sharing in a community is that fellow members can act as guides, helping other users to find the information that they are looking for. The communities also act as an information hub - bringing different sources together and saving members from having to spend hours searching through a myriad of separate resources. Most members view information-gathering and socialising as a separate activity, although a significant number feel that these activities are one and the same.

In addition, the results also show that the majority of members think that their mailing list or message board can be classed as a 'community', and some even feel that it is more like a 'family'. However, I feel that virtual communities are of a different form. It is inappropriate to rigidly apply archaic notions of traditional community life to the new technology of CMC.

\section{Note}

This article was first published by HERO (http://www.hero.ac.uk) and is reprinted here by their kind permission. 